\title{
Study on the Coating Surface Characteristics of Coated Paper
}

\author{
Ying $\mathrm{Li}^{1,}$, , Qinming Wang ${ }^{1}$, Wenjuan $\mathrm{Gu}^{1}$ and Banggui $\mathrm{He}^{1}$ \\ ${ }^{1}$ Faculty of Mechanical and Electrical Engineering, Kunming University of Science and Technology, \\ Kunming, 650093, China \\ ${ }^{a}$ Corresponding author:haishanying@126.com
}

Keywords: Contact angle; Surface microstructure; Surface characteristics; OCA; AFM

\begin{abstract}
The surface physical and chemical properties of coating layer have an important effect on the final printing quality. In this study, the main aim was to investigate into the surface characteristics and surface microstructure of coating layer. The surface chemical property was explored by OCA to obtain contact angle and surface free energy. The surface microstructure was explored in the method of visual analysis using atomic force microscopy (AFM). The conclusions indicated that drying temperature affected the characteristics and microstructure of the coated paper surface. It could be concluded that the moderate drying temperature in the consolidation phase of coating color made a contribution to the forming of the coating layer, which made the coating surface highly smooth. Surface water hydrophilic decreased and Surface water repellency increased with drying temperature adding.
\end{abstract}

\section{Introduction}

The coating structure and surface topography are dependent on factors such as pore structure, coating color formulation, particle arranging, coating speed and drying temperature, et $[1,2]$. The surface characteristics and structure are often critical to properties, which play a major role in determining print gloss, print density and appearance of final printing [3, 4]. The main objective of this study was to investigate the effect of drying temperature on surface properties and microstructure of coating layer. To this aim, the coated samples with different drying temperature were studied, by measuring the surface contact angle, surface free energy, surface properties and surface microstructure of these coatings. Drying temperature was critical to the surface topography and structure, which played a major role in determining print gloss, print density and appearance of final printing.

\section{Experimental}

Coating Samples. The pigment used for coating was fine Kaolin pigments (supplied by Mao Ming Clay Company, China). The basis weight of the woodfree base paper (supplied by Dong Tang Paper Mill) was $70 \mathrm{~g} / \mathrm{m}^{2}$. The coatings of paper were composed with 100 parts kaolin pigment and different parts carboxylic styrene-butadiene latex (supplied by BASF Company, China) with typical types of appropriate additives. The coating formulations were in Table 1. Coating was performed with a bar coater (model K303 Multi-coater, RK Print Coat Instruments Ltd, United Kingdom) with a coating speed of $4 \mathrm{~m} \mathrm{~min}^{-1}$ and coating thickness of $4 \mu \mathrm{m}$. The coated paper was moved to a drying oven for drying with a series of drying temperature of $100-190^{\circ} \mathrm{C}$ for $1 \mathrm{~min}$.

Printing. Ink films (TOKA offset printing fast-drying Cyan ink, Japan)were applied to the coated paper strips using a laboratory printing tester (model IGT Global standard Tester 2, America) and ink distribution apparatus (model IGT Speed Inking Unite 4) with a printing pressure of $625 \mathrm{~N}$ and a printing speed of $0.2 \mathrm{~m} / \mathrm{s}$.

AFM. In order to characterize the coating surface microstructure, the atomic force microscopy (AFM) used was a commercial Nanoscope IIIa from Digital Instruments (Santa Barbara, CA). The images of surface topography were captured with tapping mode in air using standard Si3N4cantilevers. Adhesion and height images were captured simultaneously. The AFM maps must be treated with flattening order before measurements. Surface plot, depth, roughness and section 
measurements were carried out using the Nanoscope IIIa image analysis software.

Table 1 Coating color recipes

\begin{tabular}{ccccc}
\hline Sample & $\begin{array}{c}\text { Kaolin } \\
\left(\mathrm{pph}^{*}\right)\end{array}$ & $\begin{array}{c}\mathrm{SB} \\
\left(\mathrm{pph}^{*}\right)\end{array}$ & $\begin{array}{c}\text { Solids } \\
(\%)\end{array}$ & $\begin{array}{c}\text { Drying } \\
\text { Temperature }\left({ }^{\circ} \mathrm{C}\right)\end{array}$ \\
\hline A1 & 100 & 15 & 60 & 100 \\
A2 & 100 & 15 & 60 & 130 \\
A3 & 100 & 15 & 60 & 160 \\
A4 & 100 & 15 & 60 & 190 \\
\hline
\end{tabular}

*Parts per hundred

Measurement of Contact Angle and Surface Free Energy. Contact angle measurements were carried our using apparatus equipped with a video camera and computer software (OCA 20 and SCA 20, Data Physics Instruments). Both coated surface of sample A, B, C and D were investigated. Distilled water was used as probe liquid. Distilled water droplet was deposited on the paper surface by a micro-syringe. Contact angle value was measured after reaching its equilibrium on the paper surface. The surface free energy was calculated from contact angle values for coated or non-coated surface of the paper samples.
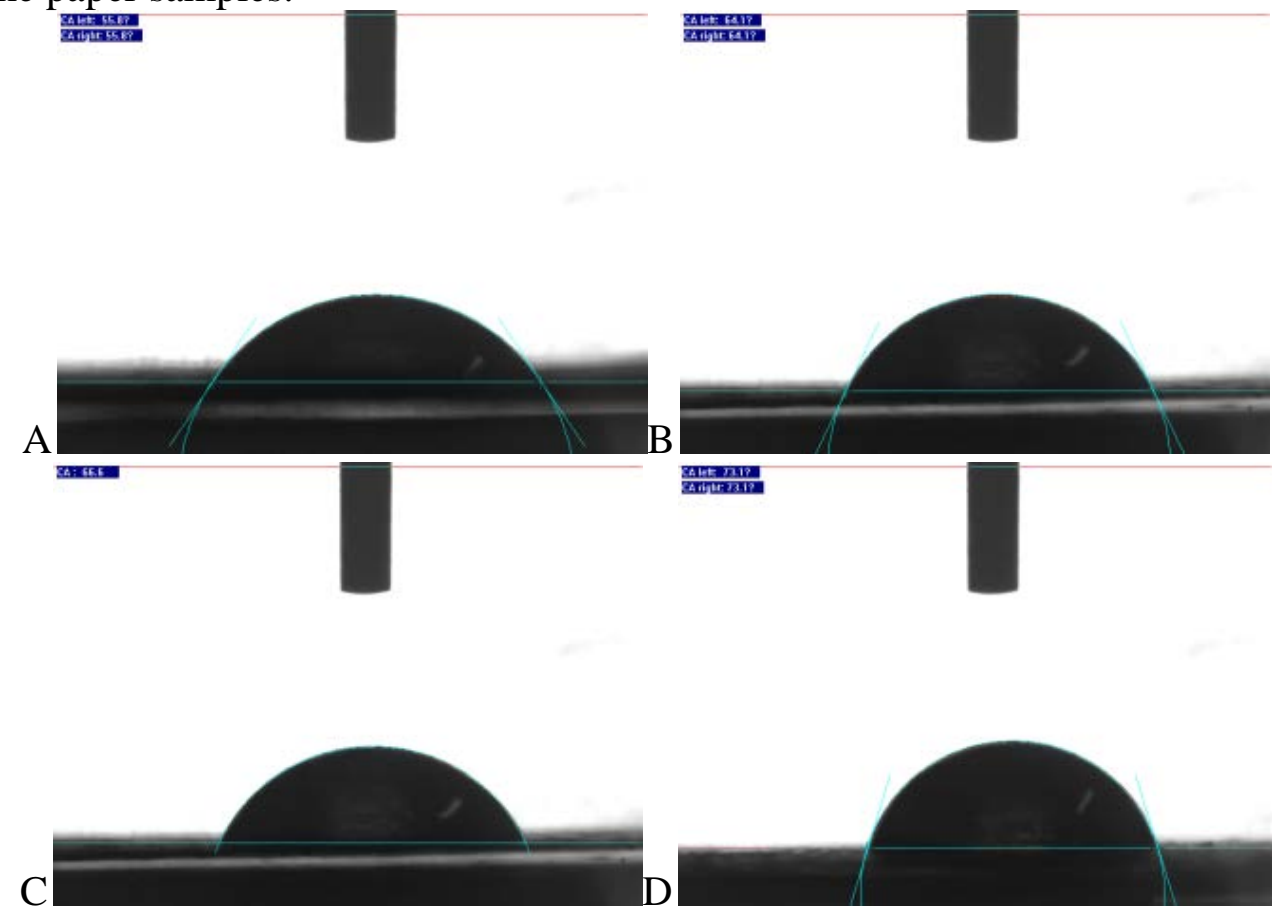

Fig.1 Contact angle measured by OCA

\section{Results and Discussion}

Contact Angle and Surface Free Energy of Coated Paper. To characterize the surface free energy of different coating surface, contact angle measurements were used. The contact angle could be described by the Young equation [5]. The balance of the forces (surface tensions) acting the triple line Young's equation [6, 7]. Fig.1 showed images of interactions of liquid and solid in this experiment for the different coating surface. The contact angles of all the coatings were quite different shown in Fig.2. The contact angle values of sample A, B, C and D with different coating surface were $55.8^{\circ}, 64.1^{\circ}, 66.6^{\circ}$ and $73.1^{\circ}$.

Surface free energy could show the surface chemical properties. Surface free energy was high and surface water hydrophilic was good, but Surface free energy was low and surface water repellency was good. Surface free energy values of sample A, B, C and D were shown in Fig.2. The results indicated the surface free energy of sample D was lowest and surface water repellency was highest. Surface free energy of sample A was highest and surface water hydrophilic was highest. It could be concluded that contact angle increased with drying temperature increasing, which 
indicated that surface water hydrophilic decreased and repellency increased with drying temperature increasing.

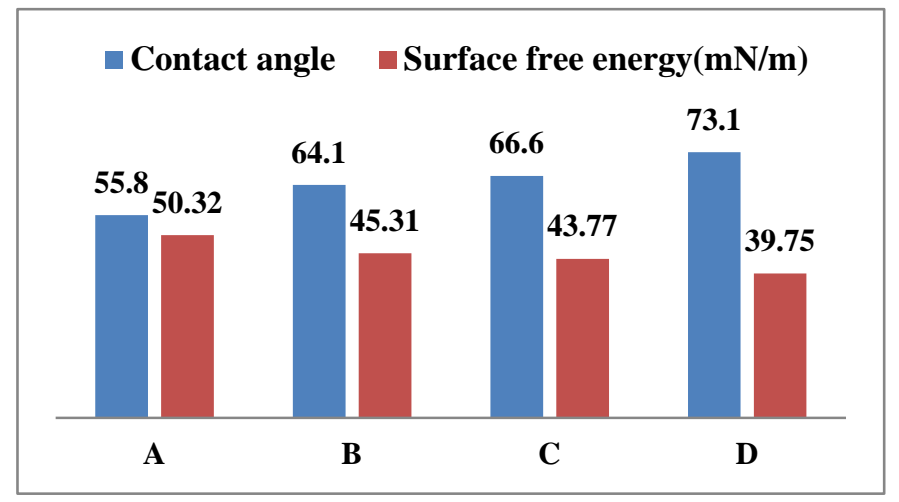

Fig.2 Contact angle and surface free energy of coated papers

Research on Surface characteristics of Coated Paper. Changes in roughness, paper gloss, ink absorption, paper surface efficiency, and print gloss of coating layer which dried at different temperature are shown in Fig. 3. The coating layer composition of samples was same, but coating dried from A to D with the drying temperature adding. Sample $\mathrm{C}$ had the lowest roughness and highest gloss compared with the other samples. This is because at low and high drying temperature, the pigment particles and binder are expected to arrange more randomly. It could be obtained that the ink absorption decreased with the increasing of drying temperature. The Results showed that sample $\mathrm{C}$ had the highest paper surface efficiency owing to the low ink absorption and high gloss, which made it easy for paper to perform the printing substrate smoothly and obtain good printing products. The results suggested that high and low drying temperature were not good to improve the paper properties, which resulted in high roughness, low gloss, high ink absorption and low paper surface efficiency. The moderate drying temperature in the consolidation phase of coating was benefit to improve surface properties. The lower amount of ink penetrated into paper coating and higher amount of ink set on the surface of coated paper with mild drying, which resulted in that the lower amount of ink produced higher print density and print gloss(see Fig. 3).

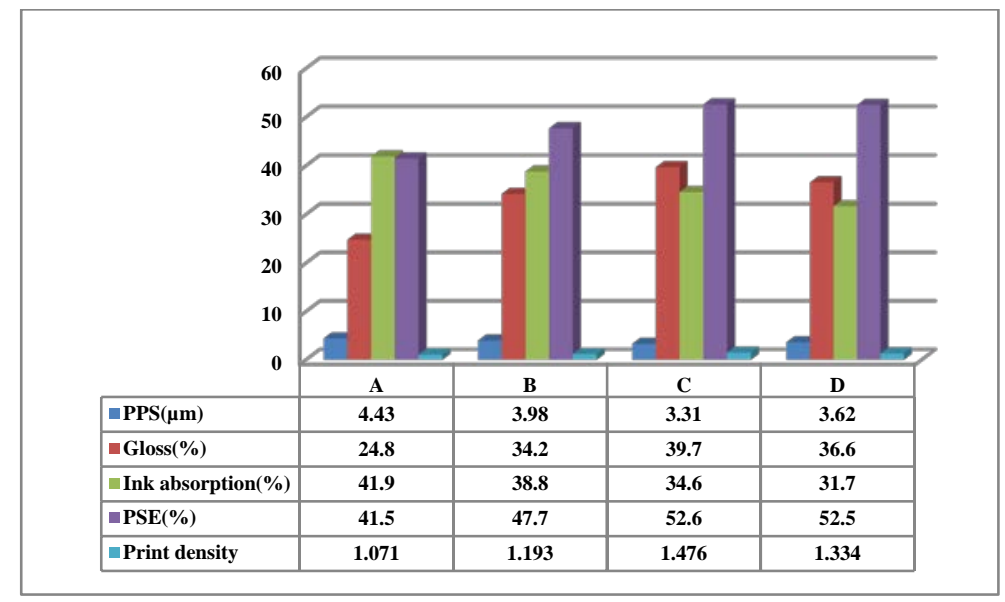

Fig.3. Surface characteristics of coated paper samples

Characterizing the Surface Microstructure. The surface topography is often critical to ink transferring behavior, which plays an important role in determining appearance of final printing. The surface depth of sample A1 was $800 \mathrm{~nm}$, and the surface depth of sample A2, A3 and A3 were $600 \mathrm{~nm}, 350 \mathrm{~nm}$ and $700 \mathrm{~nm}$, respectively. When the samples were compared, the findings suggested that drying temperature affected the pore size and distribution of the coating surface. The roughness parameter values were determined by the scanned area and a $10 \mu \mathrm{m} \times 10 \mu \mathrm{m}$ image size was considered to be suitable to describe the surface roughness of the papers. It was found that the pore depth of sample A1 was deeper than sample A2, A3 and A4. Mean-line profile curves of samples were shown in Fig.4 and the mean roughness (Ra) value over the map of sample A1 was calculated 
as $246.1 \mathrm{~nm}$. The depth range of Fig.4 showed similar maps for sample A2, A3 and A3. Here the mean roughness $(\mathrm{Ra})$ values for topography maps were $184.56 \mathrm{~nm}, 103.69$ and $167.52 . \mathrm{nm}$, which were in accord with the result in Fig.3.

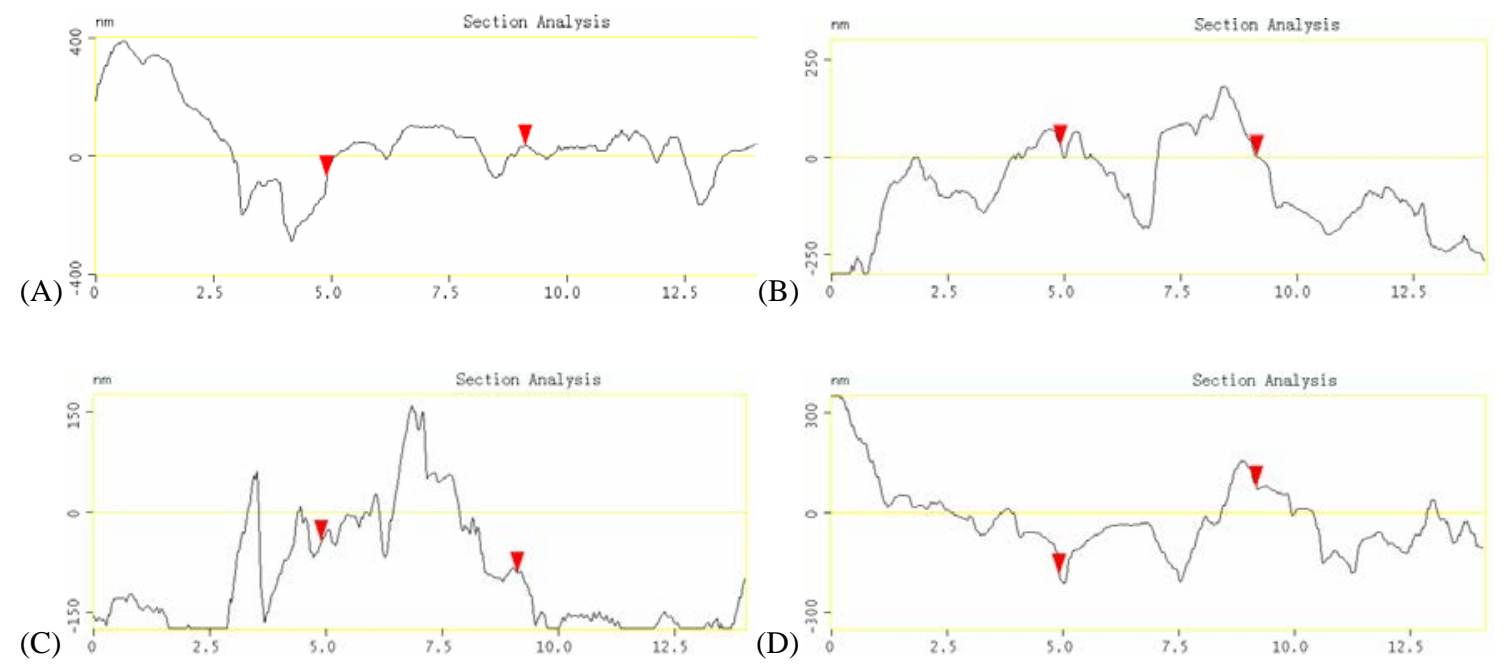

Fig.4 sectional analysis (Area: $10 \mu \mathrm{m} \times 10 \mu \mathrm{m})$

\section{Conclusions}

In this research, the results obtained were explored as the basis for discussion about the effect of drying on surface characteristics and microstructure of coating samples. The conclusions were drawn that drying temperature affected the pore size, depth and distribution of the coated paper surface owing to the different properties on the coating surface. The results showed that contact angle increased with drying temperature increasing, which indicated that surface water hydrophilic decreased and repellency increased with drying temperature increasing. Low drying temperature and high drying temperature could not contribute to improve the coating surface topography and the formation of good surface characteristics, but moderate temperature was benefit to improve coating properties.

\section{Acknowledgements}

The authors express their gratitude to the Yunnan Province Science and Technology Department (Project KKSY 2012/01059 and KKSY 2012/01051) for financial support.

\section{References}

[1] D.O. Cummings and A.V. Lyons: Proceeding TAPPI Coating Conference, TAPPI Press, Nashville, Atlanta, 1996, p.16.

[2] J.S. Preston, N.J. Elton, A. Legrix and C. Nutbeem: Proceeding of TAPPI Advanced Coating Fundamentals Symposium, San Diego, May 2001.

[3] Y. Xiang, D. Desjumaux, D. Bousfield and M.F. Forbes: Preprints of the Pan Pacific and International Printing and Graphic Arts Conference, Quebec, 1998, p. 85.

[4]K. Yamazaki, T. Nishioka, Y. Hattori: Tappi J. 76(5) (1933), p.79.

[5] G. Whyman, E. Bormashenko, T. SteinElton: Chem. Phys. Lett. 450 (2008), p.355.

[6] B. He, J. Lee, N. A.Patankar: Collids Surf. A. 248(2004) p.101.

[7] P. Letellier, A. Mayaffre, M. Turmine: Colloid Interface. Sci. J. 314(2007), p.604. 